Corrigendum

\title{
Corrigendum to "The Antiosteoporosis Effects of Yishen Bugu Ye Based on Its Regulation on the Differentiation of Osteoblast and Osteoclast"
}

\author{
Yangyang Li $\mathbb{D}^{1},{ }^{1}$ Yongfeng Zhang $\mathbb{D}^{2},{ }^{2}$ Weiqi Meng $\mathbb{D}^{2},{ }^{2}$ Yutong Li $\mathbb{D}^{1},{ }^{1}$ Tao Huang $\mathbb{D},{ }^{3}$ \\ Di Wang $\left.{ }^{(D}\right)^{2}$ and Min $\mathrm{Hu} \mathbb{D}^{1}$ \\ ${ }^{1}$ Department of Orthodontics, School and Hospital of Stomatology, Jilin University, Changchun 130021, China \\ ${ }^{2}$ School of Life Sciences, Jilin University, Changchun 130012, China \\ ${ }^{3}$ Changchun University of Chinese Medicine, Changchun 130117, China
}

Correspondence should be addressed to Di Wang; jluwangdi@jlu.edu.cn and Min Hu; humin@jlu.edu.cn

Received 1 April 2021; Accepted 1 April 2021; Published 17 April 2021

Copyright (C) 2021 Yangyang Li et al. This is an open access article distributed under the Creative Commons Attribution License, which permits unrestricted use, distribution, and reproduction in any medium, provided the original work is properly cited.

In the article titled "The Antiosteoporosis Effects of Yishen Bugu Ye Based on Its Regulation on the Differentiation of Osteoblast and Osteoclast" [1], the authors identified a mistake in Figure 1, where panel 2 of the liver samples was duplicated with panel 6 . The authors confirm that this does not affect the results and conclusions of the article, and the corrected Figure 1 is as follows: 


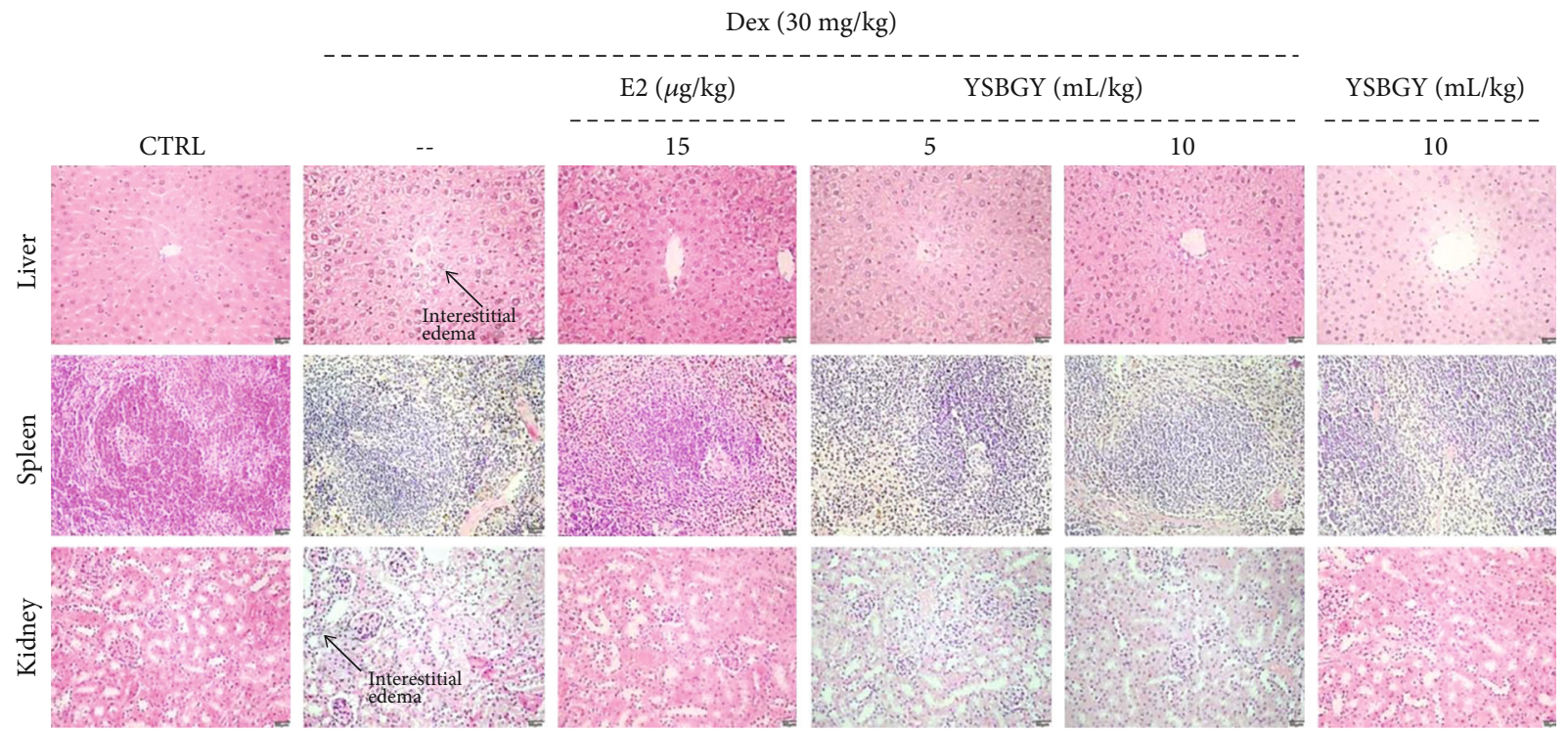

FIGURE 1: Effects of YSBGY on the structures of the liver, spleen, and kidney of OP mice visualized by H\&E staining $(n=6$; 200x, scale bar: $50 \mu \mathrm{m})$.

\section{References}

[1] Y. Li, Y. Zhang, W. Meng et al., “The Antiosteoporosis Effects of Yishen Bugu Ye Based on Its Regulation on the Differentiation of Osteoblast and Osteoclast," BioMed Research International, vol. 2020, Article ID 9467683, 12 pages, 2020. 